\title{
EFFECT OF TRANSFERSOME FORMULATION ON THE STABILITY AND ANTIOXIDANT ACTIVITY OF N-ACETYLCYSTEINE IN ANTI-AGING CREAM
}

\author{
HARMITA HARMITA*, ISKANDARSYAH ISKANDARSYAH, SHOFIYAH FATIN AFIFAH
}

Department of Pharmacy, Faculty of Pharmacy, Universitas Indonesia, Depok, West Java, Indonesia. Email: igakadeharmita@gmail.com

Received: 26 September 2019, Revised and Accepted: 17 December 2019

ABSTRACT

Objective: $\mathrm{N}$-acetylcysteine is an antioxidant with thiol/sulfhydryl groups and is currently being developed as an active ingredient in anti-aging creams. The study's aim was to compare the stability and antioxidant activity of $\mathrm{N}$-acetylcysteine in anti-aging creams formulated with and without a transfersome carrier system.

Methods: Stability was assessed by performing cycling, centrifugal, and accelerated stability tests. In addition, antioxidant activity was measured by the DPPH method, and in vitro penetration was measured using Franz diffusion cells. The analysis of N-acetylcysteine was performed using highperformance liquid chromatography with ultraviolet-visible detection at a wavelength of $214 \mathrm{~nm}$ and a flow rate of $1.0 \mathrm{~mL} / \mathrm{min}$, injection volume of $5 \mu \mathrm{L}$, and a mobile phase of phosphate buffer $\mathrm{pH} 3.0$.

Results: The N-acetylcysteine transfersome and non-transfersome cream preparations did not change color or show phase separation during the cycling and centrifugal tests. The $\mathrm{N}$-acetylcysteine in the transfersome and non-transfersome cream preparations had strong antioxidant activity, with half-maximal inhibitory concentrations of $26.90 \mu \mathrm{g} / \mathrm{mL}$ and $38.63 \mu \mathrm{g} / \mathrm{mL}$, respectively. The in vitro penetration test using Franz diffusion cells showed that the cumulative amount of penetrated N-acetylcysteine was $7355.13 \mu \mathrm{g} / \mathrm{cm}^{2}$ (flux of $845.67 \mu \mathrm{g} / \mathrm{cm}^{2} \cdot \mathrm{h}$ ) in the transfersome cream and $4677.61 \mu \mathrm{g} / \mathrm{cm}^{2}$ (flux of $533.33 \mu \mathrm{g} / \mathrm{cm}^{2} \cdot \mathrm{h}$ ) in the non-transfersome cream.

Conclusion: The in vitro penetration test results showed that the transfersome formulations in creams were able to increase the cumulative amount and flux of penetrated $\mathrm{N}$-acetylcysteine in anti-aging cream preparations relative to those not formulated with transfersome.

Keywords: N-acetylcysteine, Transfersome, Anti-aging, Stability, Antioxidant, High-performance liquid chromatography.

(C) 2020 The Authors. Published by Innovare Academic Sciences Pvt Ltd. This is an open access article under the CC BY license (http://creativecommons. org/licenses/by/4. 0/) DOI: http://dx.doi.org/10.22159/ijap.2020.v12s1.FF034

\section{INTRODUCTION}

Signs of aging can be partly prevented and slowed using various methods, one of which is the application of cosmetics. Cosmetics that are currently widely used to mask or slow signs of aging of the skin are called anti-aging cosmetics. Anti-aging products on the market are available in various dosage forms, one of which is a cream. Creams are generally preferred as topical dosage forms because cream is easily applied and easily removed from the skin [1]. Anti-aging cream products available on the market generally use an antioxidant as the active ingredient. Antioxidants are simple molecules that can prevent cell damage caused by oxidation stimulated by other molecules [2]. An antioxidant that has recently been developed as an active ingredient in anti-aging creams is $\mathrm{N}$-acetylcysteine.

$\mathrm{N}$-acetylcysteine is an antioxidant derived from the amino acid L-cysteine. N-acetylcysteine contains thiol/sulfhydryl (R-SH/-SH) groups, which are antioxidants [3]. $\mathrm{N}$-acetylcysteine can prevent and/ or inhibit the oxidative process as measured by different biomarkers of oxidative stress [4]. N-acetylcysteine can act as a direct antioxidant and indirect antioxidant. The mechanism of direct antioxidation involves a free thiol group that can interact directly with electrons from reactive oxygen species. In addition, $\mathrm{N}$-acetylcysteine also can act as an indirect antioxidant because it can undergo deacetylation to cysteine, which is an intracellular reduced glutathione precursor that can increase glutathione levels in the body $[3,4]$.

$\mathrm{N}$-acetylcysteine is not stable under oxidative conditions because it is easily oxidized when formulated. Stabilization strategies are needed to maintain the stability of $\mathrm{N}$-acetylcysteine formulations for use as antioxidative anti-aging creams. One strategy to maintain the stability of $\mathrm{N}$-acetylcysteine is to formulate it with a transfersome carrying system [5]. The study's aim was to test the effects of transfersome systems on the stability and antioxidant activity of $\mathrm{N}$-acetylcysteine in anti-aging formulations.

\section{MATERIALS AND METHODS}

\section{Instrumentation}

The following instrumentation was used: High-performance liquid chromatography (HPLC) (Model LC-20AT; Shimadzu, Japan); rotary vacuum evaporator (Buchi, Switzerland); ultraviolet (UV)-visible spectrophotometer (Shimadzu UV-1601 and Jasco Climate Chamber; Nuve Sanayi Malzemeleri Imalat ve Tic. A.S., Turki); vortex mixer (Thermo Scientific, America); centrifuge (Hettich Centrifugen EBA 200); microcentrifuge (Thermo Fisher Scientific); sonicator (Branson 3200); particle size analyzer (Malvern Zetasizer, Inggris); oven (Memmert); refrigerator (GEA, Germany); and Franz diffusion cell.

\section{Materials}

N-acetylcysteine standard (Daebong LS Co. LTD., Korea Selatan); phosphatidylcholine (Merck, Germany); Tween 80 (Merck); potassium dihydrogen phosphate (Merck, Germany); phosphoric acid (Merck); sodium hydroxide (Merck); sodium metabisulfite (Merck); dichloromethane p.a (Merck); distilled water (Ikapharmindo Putramas); and methanol (Merck) were used.

Preparation of mobile phase potassium dihydrogen phosphate pH 3.0

A $6.8 \mathrm{~g}$ amount of potassium dihydrogen phosphate was dissolved in $1000 \mathrm{~mL}$ of distilled water, adjusted with phosphoric acid to a $\mathrm{pH} 3.0$, filtered, and degassed. 
Preparation of sodium metabisulfite solution

A $0.25 \mathrm{~g}$ amount of sodium metabisulfite was dissolved in $500 \mathrm{~mL}$ of distilled water, freshly prepared [6].

Preparation of $\mathrm{N}$-acetylcysteine $400 \mu \mathrm{g} / \mathrm{mL}$ standard solution A $100 \mathrm{mg}$ amount of $\mathrm{N}$-acetylcysteine standard was accurately weighed and placed in a $10 \mathrm{~mL}$ volumetric flask, dissolved, and made up to volume with sodium metabisulfite solution to give a standard stock solution of $10.000 \mu \mathrm{g} / \mathrm{mL}$. The standard stock solution was then diluted to a concentration of $1000 \mu \mathrm{g} / \mathrm{mL}$ and diluted again to give a concentration of $400 \mu \mathrm{g} / \mathrm{mL}$ [6].

\section{Determination of optimum analysis conditions}

The following general chromatographic conditions were used to analyze N-acetylcysteine: Shimpack C18 column (5 $\mu \mathrm{m}, 4.6 \times 250 \mathrm{~mm})$, sodium metabisulfite solution as solvent, potassium dihydrogen phosphate solution $\mathrm{pH} 3.0$ as mobile phase, injection volume of $5 \mu \mathrm{L}$, and detection wavelength of $214 \mathrm{~nm}$. The optimum analysis conditions were determined by varying the flow rate at $0.8,1.0$, and $1.2 \mathrm{~mL} / \mathrm{min}$. The standard $\mathrm{N}$-acetylcysteine $400 \mu \mathrm{g} / \mathrm{mL}$ test solution was injected $(\leq 5 \mu \mathrm{L})$ into the HPLC. The selected optimized chromatographic conditions were those that gave the highest peak area, a relatively short retention time (tR), the largest number of theoretical plates $(\mathrm{N})$, the smallest height equivalent to a theoretical plate (HETP; the best potential separation efficiency), and the smallest tailing factor (Tf).

\section{System suitability test}

A $5 \mu \mathrm{L}$ aliquot of the standard solution of $\mathrm{N}$-acetylcysteine $(400 \mu \mathrm{g} / \mathrm{mL})$ was injected 6 times into the HPLC under the optimum analysis conditions. The peak area, tR, N, HETP value, resolution (R), and Tf were determined and averaged. The results were obtained at the optimum wavelength and analysis conditions. The results fulfilled the system suitability test requirements of coefficient of variation $(\mathrm{CV})<2 \%$.

\section{Validation of HPLC method}

Linearity, limit of detection ( $L O D$ ), and limit of quantitation (LOQ)

A standard solution of $\mathrm{N}$-acetylcysteine $(1000 \mu \mathrm{g} / \mathrm{mL})$ was diluted to give $100,200,300,400,500$, and $600 \mu \mathrm{g} / \mathrm{mL}$ working solutions. Then, $5 \mu \mathrm{L}$ of a working solution was injected into the HPLC under the optimum analysis conditions [6]. A calibration curve was created from the peak area (y) versus the concentration of analyte (x). A linear regression equation and the correlation coefficient for the fitted curve were determined. Based on the calibration curve obtained, the LOD and LOQ were calculated. The results fulfilled linearity requirements, with a correlation coefficient $r>0.9990$.

\section{Selectivity test}

A blank solution (cream matrix) and standard solution of $\mathrm{N}$-acetylcysteine $400 \mu \mathrm{g} / \mathrm{mL}$ were prepared. A $5 \mu \mathrm{L}$ aliquot of the blank and standard solutions were separately injected into the HPLC under the optimum analysis conditions. The results of the blank and standard selectivity test chromatograms were compared, and the chromatograms were evaluated to determine if there was interference or the appearance of another peak around the tR of N-acetylcysteine. Selectivity was assessed to be good if there was no interference and no other peaks around the $\mathrm{N}$-acetylcysteine $\mathrm{tR}$.

\section{Accuracy and precision}

Accuracy and precision were determined using a simulation method (spiked-placebo recovery), which involved adding a number of pure material analytes to the carrier material for pharmaceutical preparations (placebo). Then, the mixture was analyzed under the optimum analysis conditions, and the results were compared with the analyte levels added (actual levels). The concentration used in the test of accuracy and precision of $\mathrm{N}$-acetylcysteine was $50 \%(200 \mu \mathrm{g} / \mathrm{mL})$, $100 \%(400 \mu \mathrm{g} / \mathrm{mL})$, and $150 \%(600 \mu \mathrm{g} / \mathrm{mL})$ [7]. The $50 \%$ concentration was made by mixing $20 \mathrm{mg}$ of $\mathrm{N}$-acetylcysteine standard into a $500 \mathrm{mg}$ cream matrix. The $100 \%$ concentration was made by mixing $40 \mathrm{mg}$ of $\mathrm{N}$-acetylcysteine standard into a $500 \mathrm{mg}$ cream matrix. The concentration of $150 \%$ was made by mixing $60 \mathrm{mg}$ of $\mathrm{N}$-acetylcysteine standard into a $500 \mathrm{mg}$ cream matrix. For each of these concentrations, the sample was accurately weighed and dissolved in $10 \mathrm{~mL}$ of sodium metabisulfite solution in a volumetric flask. The solution of each concentration was sonicated for $30 \mathrm{~min}$ and vortex mixed for $5 \mathrm{~min}$, then centrifuged at $4000 \mathrm{rpm}$ for $15 \mathrm{~min}$. The supernatants from each concentration were filtered through $0.45 \mu \mathrm{m}$ nylon syringe filters, and then $5 \mu \mathrm{L}$ were injected into the HPLC under the optimum analysis conditions. The $50 \%$ and $150 \%$ concentrations were analyzed with triplicate injections, and the $100 \%$ concentration was analyzed with 6 injections.

Each concentration was injected into the HPLC under the optimum analysis conditions and the peak area of $\mathrm{N}$-acetylcysteine was integrated and recorded. The percent recovery (\%UPK) was calculated by comparing the measured concentration with the actual concentration. Acceptable accuracy was a \%UPK ranging from $98 \%$ to $102 \%$. Precision was determined as the relative standard deviation or CV. Acceptable precision was a $\mathrm{CV}<2 \%$ [8].

\section{Transfersome formulation}

Transfersome formulations were prepared by a thin-layer hydration method. The transfersome formulations are presented in Table 1. Transfersome was formulated by mixing phosphatidylcholine and Tween 80 and dissolving them in dichloromethane. The solution was then placed in a round-bottom flask and evaporated on a rotary vacuum evaporator for $60 \mathrm{~min}$ at a temperature of $40^{\circ} \mathrm{C}$ and 50-150 rpm. Nitrogen gas was passed over the thin residual layer for $2 \mathrm{~min}$, and the flask was then stored in a refrigerator for $24 \mathrm{~h}$ in a closed state. The thin layer was hydrated with a phosphate buffer solution ( $\mathrm{pH} 7.4)$ containing $\mathrm{N}$-acetylcysteine in a rotary vacuum evaporator at a temperature of $30^{\circ} \mathrm{C}$ and rotation speed of $50-150 \mathrm{rpm}$ for $60 \mathrm{~min}$ with glass beads to remove the thin layer on the round flask wall. Ultrasonication was performed for $10 \mathrm{~min}$ to reduce the particle size of the solids [7,9-11].

\section{Transfersome optimization}

Particle size and polydispersity index

Determination of the particle size and polydispersity index of the transfersome formulations were determined by the dynamic light scattering method using a particle size analyzer at $25^{\circ} \mathrm{C}$. One drop of sample from each transfersome formulation was dispersed in $10.0 \mathrm{~mL}$ of distilled water and then tested for particle size.

\section{Entrapment efficiency}

Entrapment efficiency was measured by calculating the total and released $\mathrm{N}$-acetylcysteine concentrations in a transfersome suspension. The released concentration of $\mathrm{N}$-acetylcysteine measurement was obtained by dissolving $1 \mathrm{~mL}$ of transfersome suspension in $10 \mathrm{~mL}$ of sodium metabisulfite solution and then centrifuging at 13,000 rpm for 2 hat $4^{\circ} \mathrm{C}$. The supernatant was filtered and injected into the HPLC.

\section{Transfersome and non-transfersome cream preparations}

The optimum transfersome suspension was freeze-dried. A dry transfersome suspension equivalent to $5 \% \quad \mathrm{~N}$-acetylcysteine was added gradually into the cream base and then mixed by using a homogenizer at $500 \mathrm{rpm}$. In a non-transfersome cream, $\mathrm{N}$-acetylcysteine was added at $5 \%$ into the cream base and mixed using a homogenizer at $500 \mathrm{rpm}$.

Table 1: Mobile phase selection

\begin{tabular}{llll}
\hline Material & $\begin{array}{l}\text { F1 (g) } \\
\mathbf{( 9 0 : 1 0 )}\end{array}$ & $\begin{array}{l}\text { F2 (g) } \\
\mathbf{( 8 5 : 1 5 )}\end{array}$ & $\begin{array}{l}\text { F3 (g) } \\
\mathbf{( 7 5 : 2 5 )}\end{array}$ \\
\hline N-acetylcysteine & 1.5 & 1.5 & 1.5 \\
Phosphatidylcholine & 1.35 & 1.275 & 1.125 \\
Tween 80 & 0.15 & 0.225 & 0.375 \\
Phosphate buffer solution pH 7.4 & 12 & 12 & 12 \\
Total & 15 & 15 & 15 \\
\hline
\end{tabular}


Stability tests

Cycling test

The two cream samples were stored at $4^{\circ} \mathrm{C}$ for $24 \mathrm{~h}$ and then transferred to an oven at $40^{\circ} \mathrm{C} \pm 2^{\circ} \mathrm{C}$ for $24 \mathrm{~h}$, which constituted one cycle. Six more cycles were performed over 12 days. The physical conditions of creams, such as organoleptic characteristics (discoloration, odor, and homogeneity), were observed before and after the experiment.

\section{Centrifugal test}

Both cream samples were inserted into the centrifugation tube and then centrifuged at $3750 \mathrm{rpm}$ for $5 \mathrm{~h}$. After centrifugation, the sample was observed to determine if phase separation between the water and oil phases occurred.

\section{Accelerated stability testing}

Both cream samples were stored in a climate chamber with storage conditions of $40^{\circ} \mathrm{C} \pm 2^{\circ} \mathrm{C}$ and relative humidity of $70 \% \pm 5 \% \mathrm{RH}$ for 3 months. Sampling was carried out at 0, 1, 2, and 3 months and analyzed using HPLC under optimum analysis conditions.

Approximately $80 \mathrm{mg}$ of each stability test sample was accurately weighed and dissolved in $10 \mathrm{~mL}$ with sodium metabisulfite solution in a volumetric flask. The sample solution was sonicated for $30 \mathrm{~min}$ and vortex mixed for $5 \mathrm{~min}$, then centrifuged at $4000 \mathrm{rpm}$ for $15 \mathrm{~min}$. The supernatant of each sample was filtered and injected into the HPLC under the optimum analysis conditions. This procedure was performed in triplicate for each sample.

\section{Antioxidant activity test using DPPH assay}

Approximately $250 \mathrm{mg}$ of each cream sample (containing $12.5 \mathrm{mg}$ $\mathrm{N}$-acetylcysteine) was weighed accurately and placed into a $25.0 \mathrm{~mL}$ volumetric flask, dissolved, and made up to volume with methanol. The sample solution was then sonicated for $10 \mathrm{~min}$ and centrifuged at $4000 \mathrm{rpm}$ for $10 \mathrm{~min}$. The supernatant of each sample was filtered, and a $500 \mu \mathrm{g} / \mathrm{mL}$ sample stock solution was obtained. The sample stock solution was then diluted to a concentration of $100 \mu \mathrm{g} / \mathrm{mL}$ and diluted again to obtain sample concentrations of $1,5,10,15,20$, and $30 \mu \mathrm{g} / \mathrm{mL}$. A $3.0 \mathrm{~mL}$ aliquot of diphenyl picrylhydrazyl (DPPH) was added to $1.0 \mathrm{~mL}$ of each sample solution. Methanol $(1.0 \mathrm{~mL})$ and DPPH $50 \mu \mathrm{g} / \mathrm{mL}(3.0 \mathrm{~mL})$ solutions were used as a blank. The mixture was shaken for $20 \mathrm{~s}$ and incubated in a dark room at room temperature $\left(27^{\circ} \mathrm{C} \pm 2^{\circ} \mathrm{C}\right)$ for $30 \mathrm{~min}$.

The antioxidant activity was determined by measuring the absorbance of each sample by UV-visible spectrophotometry at an optimum wavelength of $515 \mathrm{~nm}$. The result obtained was used to calculate the inhibition percentage of DPPH by $\mathrm{N}$-acetylcysteine in cream samples. The percentage of DPPH radical inhibition was calculated by comparing the sample and blank results.

\section{Franz diffusion cells in vitro penetration test}

The membrane used was the abdomen skin of 2-3-month-old female Sprague-Dawley rats weighing 150-200 g. In this study, all methods for sacrificing the animals had been approved through an ethical approval certificate from the Health Research Ethics Committee, Faculty of Medicine, University of Indonesia No.184/UN2.F1/ETIK/ PPM.00.02/2019. In vitro penetration tests were performed using Franz diffusion cells with a diffusion area of $1.77 \mathrm{~cm}^{2}$ and a compartment volume of $15.0 \mathrm{~mL}$. The receptor compartment was filled with $\leq 15.0 \mathrm{~mL}$ phosphate-buffered solution $\mathrm{pH} 7.4$ and the temperature was maintained using a water jacket at $37^{\circ} \mathrm{C} \pm 0.5^{\circ} \mathrm{C}$ and stirred with a magnetic stirrer at a speed of $200 \mathrm{rpm}$. The abdominal skin was shaved and cleaned of fat and then placed between the donor and receptor compartments with the position of the stratum corneum facing up. The cream samples tested in this study were $5 \% \mathrm{~N}$-acetylcysteine transfersome cream and $5 \% \mathrm{~N}$-acetylcysteine non-transfersome cream. Each cream sample $(1 \mathrm{~g})$ was applied to the skin in the donor compartment. Sample solution $(1 \mathrm{~mL})$ was taken from the receptor compartment using a syringe at 10 , $30,60,90,120,180,240,300,360,420$, and $480 \mathrm{~min}$ and immediately refilled with the same amount of phosphate buffer $\mathrm{pH}$ 7.4. The sample solution was inserted into a vial, and its concentration was measured by HPLC under the optimum analysis conditions.

\section{RESULTS AND DISCUSSION}

\section{Determination of optimum analysis conditions}

The results of the analysis method optimization are presented in Table 2.

The flow rate chosen in this study was $1.0 \mathrm{~mL} / \mathrm{min}$ because it gave better results than those at the flow rate of $0.8 \mathrm{~mL} / \mathrm{min}$ and $1.2 \mathrm{~mL} / \mathrm{min}$. The flow rate of $1.0 \mathrm{~mL} / \mathrm{min}$ had a large peak area of $1,130,622 \mu \mathrm{V} / \mathrm{s}$, the retention time of $8.718 \mathrm{~min}$ was relatively early, and the Tf of 1.446 was the smallest of the tested conditions. The flow rate of $0.8 \mathrm{~mL} / \mathrm{min}$ was not chosen even though it had a larger peak area than that at $1.0 \mathrm{~mL} / \mathrm{min}$ because the retention time of $11.236 \mathrm{~min}$ was too long and the Tf was higher

\section{System suitability test}

The system suitability test results are presented in Table 3.

The system suitability test was performed first before analysis under the optimum analysis conditions. After injecting the $400 \mu \mathrm{g} / \mathrm{mL}$ standard

Table 2: Peak area, retention time, tailing factor, column efficiency, and theoretical plates from $\mathrm{N}$-acetylcysteine chromatograms at two eluent flow rates

\begin{tabular}{llllll}
\hline Flow rate $(\mathbf{m L} / \mathbf{m i n})$ & Peak area $(\boldsymbol{\mu V} / \mathbf{s})$ & Retention time $(\mathbf{m i n})$ & Tailing factor & HETP $(\mathbf{c m})$ & Theoretical plates $(\mathbf{N})$ \\
\hline 0.8 & $1,470,303$ & 11.236 & 1.516 & 40.187 & 3733 \\
1.0 & $1,130,622$ & 8.718 & 1.446 & 41.683 & 3599 \\
1.2 & $9,59,846$ & 7.436 & 1.454 & 44.133 & 3399 \\
\hline
\end{tabular}

Table 3: System suitability test results of $\mathrm{N}$-acetylcysteine

\begin{tabular}{llllll}
\hline Concentration $(\boldsymbol{\mu g} / \mathbf{m L})$ & $\begin{array}{l}\text { Peak area } \\
(\boldsymbol{\mu V} / \mathbf{s})\end{array}$ & $\begin{array}{l}\text { Retention time } \\
(\mathbf{m i n})\end{array}$ & Tailing factor & $\begin{array}{l}\text { Height equivalent to a } \\
\text { theoretical plate }(\mathbf{c m})\end{array}$ & $\begin{array}{l}\text { Theoretical plates } \\
(\mathbf{N})\end{array}$ \\
\hline & $1,144,078$ & 8.980 & 1.469 & 41.758 & 3592 \\
400 & $1,147,670$ & 8.979 & 1.500 & 42.551 & 3525 \\
& $1,150,640$ & 8.718 & 1.479 & 41.826 & 3586 \\
& $1,141,042$ & 8.642 & 1.498 & 41.558 & 3690 \\
Average & $1,155,160$ & 8.686 & 1.495 & 40.543 & 3600 \\
Standard deviation & $1,149,613$ & 8.620 & 1.454 & 41.596 & 3617 \\
Coefficient of variation (\%) & $1,148,033.83$ & 8.771 & 1.483 & 41.639 & 66.9141 \\
\end{tabular}


solution of $\mathrm{N}$-acetylcysteine 6 times, the coefficients of variation were $0.44 \%$ for peak area, $1.88 \%$ for retention time, $1.25 \%$ for Tf, $1.55 \%$ for HETP, and $1.85 \%$ for the number of theoretical plates (N). The CV did not exceed $2 \%$, as required [8].

\section{Validation method}

Linearity, $L O D$, and $L O Q$

The calibration curve data, LOD, and LOQ of $\mathrm{N}$-acetylcysteine are presented in Table 4.

Fig. 1 shows the calibration curve for $\mathrm{N}$-acetylcysteine. The results obtained are excellent because they have a correlation coefficient close to 1 ( $r>0.9990)$ [8]. The LOD and LOQ values were sufficiently sensitive.

\section{Selectivity test}

The chromatogram from the blank solution did not show any interference or peaks of other compounds at the retention time of $\mathrm{N}$-acetylcysteine, which supports the selectivity of the method for $\mathrm{N}$-acetylcysteine [8].

\section{Accuracy and precision}

The accuracy and precision of the method are presented in Table 5.

The precision fulfilled the requirements by giving a $\mathrm{CV}$ of $\leq 2 \%$ [8]. The method used in this study fulfilled the criteria for accuracy and precision.

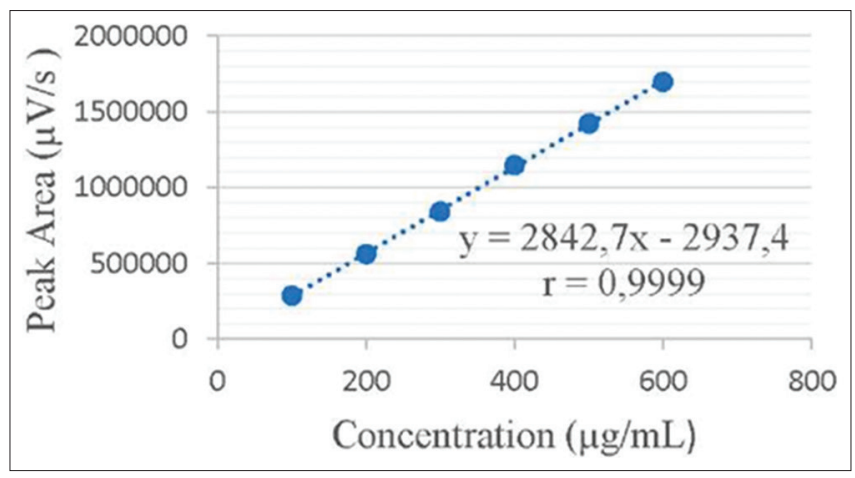

Fig. 1: Calibration curve of $\mathrm{N}$-acetylcysteine
Transfersome formulation optimization

The transfersome formulation optimization results are presented in Table 6.

\section{Particle size}

The Z-average value shows the average particle size in the preparation. The particle sizes were good and were $<200 \mathrm{~nm}$ [12]. The results show that higher concentrations of surfactant gave larger particle size [13].

\section{Polydispersity index}

The particle size distribution is reflected by the polydispersity index parameter and is used to show the particle size distribution in nanoparticle systems. The polydispersity index values ranged from 0 to 0.6 . If the value is $>0.6$, the sample has a very wide size distribution; as the value approaches zero, the particle size distribution is increasingly homogeneous. The resulting values were good because they were $<0.6$ [12]. The results showed that the distribution of particle size in F1 was the most homogeneous. The polydispersity index of each formula increased with increasing particle size [14].

\section{Entrapment efficiency}

Determination of entrapment efficiency was performed to determine the amount of active substances that were absorbed by transfersome. The highest entrapment efficiency was $65.58 \%$ for F1. The entrapment efficiency of transfersome increased with increasing lipid concentration (phospholipid) and decreased with increasing surfactant concentration because lower surfactant concentrations $(<15 \%, b / b)$ allowed all surfactant molecules to bind to the phospholipid bilayer layer. If the concentration exceeds a certain concentration, some surfactant molecules will cause an increase in the permeability of the vesicle membrane, which can reduce the efficiency of entrapment $[15,16]$. Phospholipids are the main components that form vesicles. The higher the phospholipid concentration used, the more vesicles are formed, so the absorption of active substances is also expected to be more optimal.

Based on the results of particle size and the calculation of entrapment efficiency, F1 was selected as the optimum formula for the cream preparations because it had the smallest particle size, with a Z-average of $57.76 \mathrm{~nm}$, the smallest polydispersity index value of 0.282 , and the largest entrapment efficiency of $65.58 \%$.

Table 4: Calibration curve data, LOD, and LOQ of N-acetylcysteine

\begin{tabular}{|c|c|c|c|c|c|c|}
\hline Concentration $(\mu \mathrm{g} / \mathrm{mL})$ & Peak area $(\mu \mathrm{V} / \mathrm{s})$ & $y i=a+b x$ & & $S(y / x)$ & LOD $(\mu \mathrm{g} / \mathrm{mL})$ & LOQ $(\mu \mathrm{g} / \mathrm{mL})$ \\
\hline 100 & 284,997 & $281,332.60$ & $13,427,827.36$ & & & \\
\hline 200 & 559,628 & $565,602.60$ & $35,695,845.16$ & & & \\
\hline 300 & 842,068 & $849,872.60$ & $60,911,781.16$ & 9039.00 & 9.54 & 31.80 \\
\hline 400 & $1,147,729$ & $1,134,142.60$ & $184,590,264.96$ & & & \\
\hline 500 & $1,420,344$ & $1,418,412.60$ & $3,730,305.96$ & & & \\
\hline 600 & $1,697,348$ & $1,702,682.60$ & $28,457,957.16$ & & & \\
\hline$n=6$ & & & $\sum=326,813,981.7$ & & & \\
\hline
\end{tabular}

LOD: Limit of detection, LOQ: Limit of quantitation

Table 5: Accuracy and precision data of $\mathrm{N}$-acetylcysteine

\begin{tabular}{|c|c|c|c|c|c|c|}
\hline Concentration $(\mu \mathrm{g} / \mathrm{mL})$ & $\begin{array}{l}\text { Peak area } \\
(\text { GiV/s) }\end{array}$ & $\begin{array}{l}\text { Measured conc. } \\
(\mu \mathrm{g} / \mathrm{mL})\end{array}$ & Recovery (\%) & Average (\%) & Standard deviation & Coefficient of variation (\%) \\
\hline & 570,152 & 201.60 & 100.80 & & & \\
\hline \multirow{4}{*}{200} & 573,738 & 202.86 & 101.43 & 100.96 & 0.8214 & 0.41 \\
\hline & 569,354 & 201.32 & 100.66 & & & \\
\hline & $1,146,385$ & 404.31 & 101.08 & & & \\
\hline & $1,137,370$ & 401.13 & 100.28 & & & \\
\hline \multirow[t]{5}{*}{400} & $1,140,504$ & 402.24 & 100.56 & 100.88 & 1.5621 & 0.39 \\
\hline & $1,149,383$ & 405.36 & 101.34 & & & \\
\hline & $1,146,786$ & 404.45 & 101.11 & & & \\
\hline & $1,144,255$ & 403.56 & 100.89 & & & \\
\hline & $1,733,954$ & 611.00 & 101.83 & & & \\
\hline \multirow[t]{2}{*}{600} & $1,722,616$ & 607.01 & 101.17 & 100.76 & 7.9127 & 1.31 \\
\hline & $1,690,583$ & 595.74 & 99.29 & & & \\
\hline
\end{tabular}




\section{Stability test}

Cycling test

The purpose of the cycling test was to determine the physical changes in the two creams. After testing for six cycles between $4^{\circ} \mathrm{C}$ and $40^{\circ} \mathrm{C} \pm 2^{\circ} \mathrm{C}$, the results showed that neither cream showed a color change nor a phase separation. However, the smell of the non-transfersome cream had an unpleasant sulfurous odor. Both creams showed good and stable results because they did not show phase separation and remained homogeneous. However, the transfersome cream was more stable than the non-transfersome cream because it did not experience a change in odor.

\section{Centrifugal test}

The centrifugal test was performed to determine the stability of the cream after a very strong shaking after being centrifuged at a speed of $3750 \mathrm{rpm}$ for $5 \mathrm{~h}$. This speed is equivalent to the gravitational force experienced over 1 year. After testing, the two creams did not show any separation of the water phase and oil phase, which was probably because of the use of appropriate emulsifying agents. In addition, phase separation can occur during the stirring process, but an appropriate stirring speed was used, which prevented separation during testing. Based on these results, we concluded that the two creams could withstand the force of gravity for 1 year.

\section{Accelerated stability testing}

The accelerated stability testing results are shown in Table 7. The curve of accelerated stability testing results of $\mathrm{N}$-acetylcysteine in transfersome cream and non-transfersome cream is shown in Fig. 2.

The accelerated stability test was performed to determine the stability of the two creams under conditions that can accelerate the change in stability at $40^{\circ} \mathrm{C} \pm 2^{\circ} \mathrm{C}$ and relative humidity of $70 \% \pm 5 \%$ RH for

Table 6: Transfersome optimization results

\begin{tabular}{llll}
\hline Formulation & $\begin{array}{l}\text { Z-average } \\
\text { (nm) }\end{array}$ & $\begin{array}{l}\text { Polydispersity } \\
\text { index (nm) }\end{array}$ & $\begin{array}{l}\text { Entrapment } \\
\text { efficiency (\%) }\end{array}$ \\
\hline F1 & 57.76 & 0.282 & 65.58 \\
F2 & 62.62 & 0.349 & 62.19 \\
F3 & 102.4 & 0.385 & 59.72 \\
\hline
\end{tabular}

Table 7: Accelerated stability testing results

\begin{tabular}{lll}
\hline Sample & \multicolumn{2}{c}{ Average remaining level of N-acetylcysteine (\%) } \\
\cline { 2 - 3 } & Transfersome cream & Non-transfersome cream \\
\hline Month 0 & 99.67 & 99.69 \\
Month 1 & 94.71 & 86.06 \\
Month 2 & 85.31 & 52.97 \\
Month 3 & 82.92 & 48.47 \\
\hline
\end{tabular}

3 months. Storage of cream under accelerated conditions can result in a decrease in the level of $\mathrm{N}$-acetylcysteine. This caused the remaining $\mathrm{N}$-acetylcysteine levels in the transfersome creams after 3 months to be $82.92 \%$ and non-transfersome creams to be $48.47 \%$.

Decreased levels of $\mathrm{N}$-acetylcysteine in transfersome cream and nontransfersome cream preparations can occur because of an oxidation reaction in $\mathrm{N}$-acetylcysteine compounds. $\mathrm{N}$-acetylcysteine is easily oxidized to the disulfide form, $\mathrm{N}, \mathrm{N}$-diacetylcysteine $[17,18]$. The easily oxidized group is the thiol/sulfhydryl (-SH) group. Decreasing levels in cream preparations can also be caused by other factors, such as the presence of water in the cream, the effect of temperature, and the effect of humidity under accelerated conditions [19].

Transfersome is a carrier system that is the development of liposomes. Transfersomes have almost the same properties as liposomes, but a transfersome has a deformability that can increase drug penetration through the skin [13]. Transfersome formulations in creams can increase the stability of $\mathrm{N}$-acetylcysteine because transfersome vesicles can protect the active substance so that contact with oxidizing agents can be avoided. In non-transfersome creams, $\mathrm{N}$-acetylcysteine compounds are not coated by a vesicle transfersome, so they are easily oxidized. This leads to lower $\mathrm{N}$-acetylcysteine levels in non-transfersome creams than those in transfersome creams [19].

$\mathrm{N}$-acetylcysteine that has been formulated in the form of transfersomes can show decreased levels, similar to those in non-transfersome creams. This can be because the entrapment efficiency in the optimum transfersome formulation used was $65.58 \%$, so there is still some free $\mathrm{N}$-acetylcysteine that can be oxidized as in a non-transfersome cream. In addition, decreased $\mathrm{N}$-acetylcysteine levels can also be caused by damage to the transfersome vesicles due to the degradation of the lipid bilayer as temperature increases. Lipid degradation can also occur because of chemical degradation processes that can affect the stability of the phospholipid bilayer, such as hydrolysis and lipid oxidation. Degradation of the lipid bilayer can reduce the absorption efficiency of $\mathrm{N}$-acetylcysteine so that more free $\mathrm{N}$-acetylcysteine is oxidized [15].

Based on the average level of $\mathrm{N}$-acetylcysteine remaining in the two cream samples, the shelf life of each cream was calculated using a zero-order stability test. Based on the calculated results, the shelf life of transfersome cream $\mathrm{N}$-acetylcysteine was 3 months 10 days, and the shelf life of non-transfersome cream $\mathrm{N}$-acetylcysteine was 1 month 2 days. Based on these results, we concluded that the transfersome formulation in the preparation of anti-aging cream $\mathrm{N}$-acetylcysteine can increase the stability of $\mathrm{N}$-acetylcysteine in anti-aging cream preparations.

\section{Antioxidant activity test using DPPH assay}

DPPH is a stable free radical compound that has one free electron on its nitrogen atom. This test is based on the principle that DPPH accepts hydrogen atoms $(\mathrm{H})$ from antioxidant molecules, which results in a more stable DPPH-H reduced form. The purple color in the DPPH

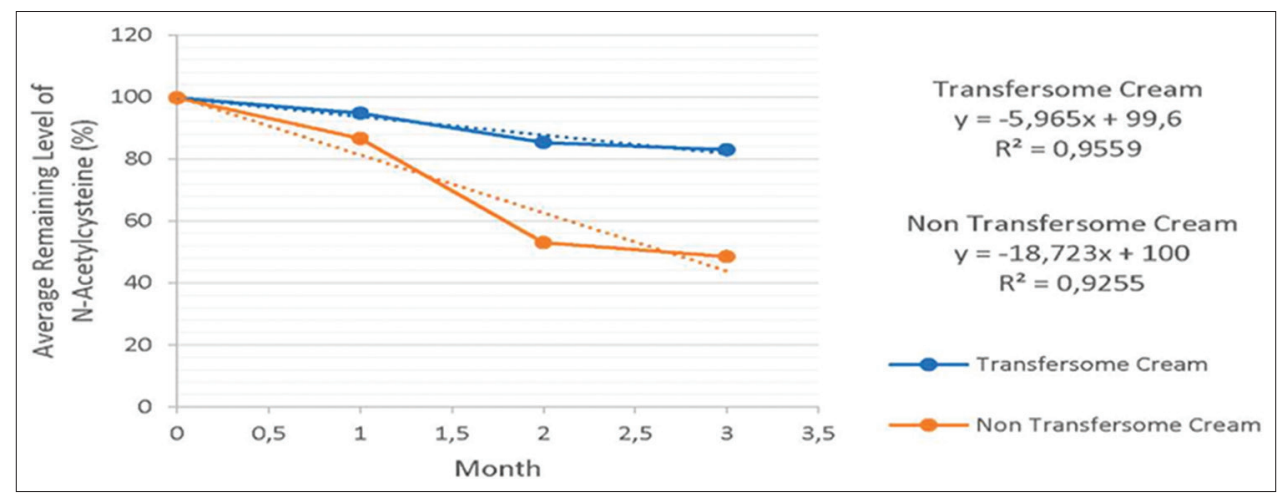

Fig. 2: The curve of accelerated stability testing results of $\mathrm{N}$-acetylcysteine in transfersome cream and non-transfersome cream 
solution will turn yellow as electrons are captured by DPPH, which indicates an increase in the reduced form of DPPH-H [20-23].

The maximum DPPH wavelength was $515 \mathrm{~nm}$ and was used to measure the antioxidant activity of the sample. The half-maximal inhibitory concentration $\left(\mathrm{IC}_{50}\right)$ of $\mathrm{N}$-acetylcysteine was $26.90 \mu \mathrm{g} / \mathrm{mL}$ in transfersome cream and $38.63 \mu \mathrm{g} / \mathrm{mL}$ in non-transfersome cream. A compound is said to have very strong antioxidant activity if the $\mathrm{IC}_{50}$ is $<10 \mu \mathrm{g} / \mathrm{mL}$, strong if it is between 10 and $50 \mu \mathrm{g} / \mathrm{mL}$, moderate if it is between 50 and $100 \mu \mathrm{g} / \mathrm{mL}$, weak if it is between 100 and $250 \mu \mathrm{g} / \mathrm{mL}$, and not active if it is $>250 \mu \mathrm{g} / \mathrm{mL}$ [24]. Based on the results obtained, $\mathrm{N}$-acetylcysteine in the transfersome and non-transfersome creams had strong antioxidant activity because the $\mathrm{IC}_{50}$ was between 10 and $50 \mu \mathrm{g} / \mathrm{mL}$ [24]. The $\mathrm{IC}_{50}$ value is the concentration of antioxidant compounds needed to inhibit $50 \%$ of existing DPPH activities. Smaller $\mathrm{IC}_{50}$ values have a stronger potential for antioxidant activity in these compounds. $\mathrm{N}$-acetylcysteine is an antioxidant derived from the amino acid L-cysteine, in which the group that is an antioxidant is a thiol/sulfhydryl group (-SH) [3]

The DPPH method antioxidant activity test results of anti-aging cream $\mathrm{N}$-acetylcysteine are shown in Table 8.

\section{Franz diffusion cells in vitro penetration test}

In vitro penetration tests have two main parameters: The cumulative amount of penetrated active substances $\left(\mu \mathrm{g} / \mathrm{cm}^{2}\right)$ and penetration rate

Table 8: DPPH method antioxidant activity test results of antiaging cream $\mathrm{N}$-acetylcysteine

\begin{tabular}{lll}
\hline Sample & Linear regression & $\mathbf{I C}_{\mathbf{5 0}}(\mu \mathrm{g} / \mathrm{mL})$ \\
\hline $\begin{array}{l}\text { Transfersome cream } \\
\text { N-acetylcysteine }\end{array}$ & $\mathrm{y}=0.5417 \mathrm{x}+35.43$ & 26.90 \\
& & \\
Non-transfersome cream & $\mathrm{y}=0.9979$ & \\
N-acetylcysteine & & 38.63 \\
& $\mathrm{r}=0.9980$ & \\
\hline
\end{tabular}

Table 9: DPPH method antioxidant activity results of anti-aging cream $\mathrm{N}$-acetylcysteine

\begin{tabular}{lll}
\hline Sample & $\begin{array}{l}\text { Cumulative amount } \\
\text { of } \mathbf{N}-\text { acetylcysteine } \\
\text { penetrated }\left(\boldsymbol{\mu g} / \mathbf{c m}^{2}\right)\end{array}$ & $\begin{array}{l}\text { Flux value of } \\
\mathbf{N} \text {-acetylcysteine } \\
\left(\boldsymbol{\mu g} / \mathbf{c m}^{-2} / \mathbf{h}\right)\end{array}$ \\
\hline $\begin{array}{l}\text { Transfersome cream } \\
\text { N-acetylcysteine }\end{array}$ & 7355.13 & 919.39 \\
$\begin{array}{l}\text { Non-transfersome cream } \\
\text { N-acetylcysteine }\end{array}$ & 4677.61 & 584.70 \\
\hline
\end{tabular}

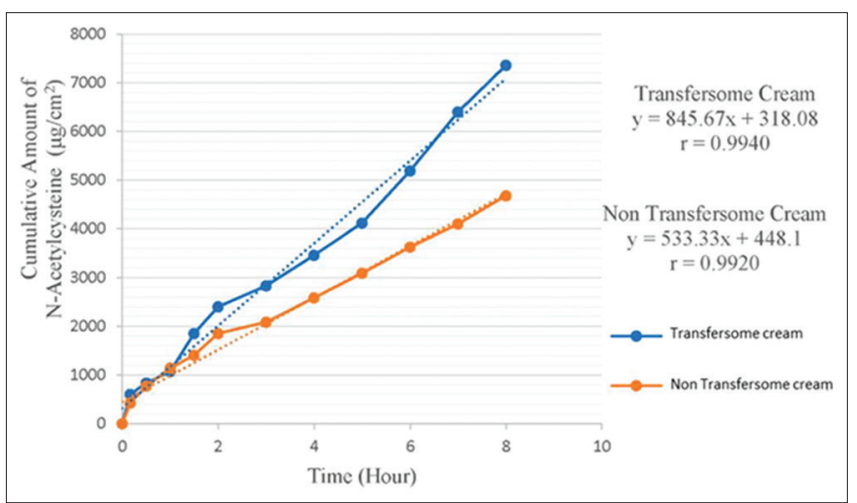

Fig. 3: The cumulative amount of $\mathrm{N}$-acetylcysteine penetrated and flux from $\mathrm{N}$-acetylcysteine transfersome and non-transfersome cream preparations (flux) $[8,25,26]$. Based on the results obtained after $8 \mathrm{~h}$ of sampling, the cumulative amount of $\mathrm{N}$-acetylcysteine penetrated was greater in the transfersome cream $\left(7355.13 \mu \mathrm{g} / \mathrm{cm}^{2}\right)$ than in the non-transfersome cream $\left(4677.61 \mu \mathrm{g} / \mathrm{cm}^{2}\right)$. In addition, the flux values obtained from the slope taken from the linear curve at steady state were based on Fick's First Law. Flux values in the steady-state were higher for the transfersome cream preparations $\left(845.67 \mu \mathrm{g} / \mathrm{cm}^{2} \cdot \mathrm{h}\right)$ than for the nontransfersome $\mathrm{N}$-acetylcysteine creams $\left(533.33 \mu \mathrm{g} / \mathrm{cm}^{2} \cdot \mathrm{h}\right)$. These results prove that the penetration rates of $\mathrm{N}$-acetylcysteine were faster from the transfersome cream preparations than from the $\mathrm{N}$-acetylcysteine non-transfersome cream.

Theresults of thepenetrationtests performedon thetransfersomecreams and $\mathrm{N}$-acetylcysteine non-transfersome creams showed a significant difference. Formulating $\mathrm{N}$-acetylcysteine into a transfersome cream increased the cumulative amount and in vitro flux of $\mathrm{N}$-acetylcysteine in anti-aging creams relative to those of the non-transfersome creams. In the transfersome creams, vesicular transfersomes act as penetration enhancers because the vesicles enter the stratum corneum and then modify the intracellular lipid lamellae. Transfersome vesicles facilitate penetration of $\mathrm{N}$-acetylcysteine through the lipid bilayer membrane of the skin stratum corneum, which has pores smaller than the size of the drug itself. In addition, phospholipids have a high affinity for biological membranes, so incorporation of phospholipid bilayer vesicles with intracellular lipid layers onto the skin through a cream can contribute to increased permeability of transfersome $[9,16,27]$.

The antioxidant activity results of anti-aging cream $\mathrm{N}$-acetylcysteine are shown in Table 9. The cumulative amount of $\mathrm{N}$-acetylcysteine penetrated and flux from $\mathrm{N}$-acetylcysteine transfersome and nontransfersome cream preparations are shown in Fig. 3.

\section{CONCLUSION}

The optimum HPLC analysis conditions for analyzing N-acetylcysteine compounds in anti-aging creams were identified and found to be suitable for future analyses. The optimum transfersome formulation used in the anti-aging cream $\mathrm{N}$-acetylcysteine preparations had an entrapment efficiency of $65.58 \%$, a particle size of $57.76 \mathrm{~nm}$, and a polydispersity index of 0.282 . Based on the results of the stability test, $\mathrm{N}$-acetylcysteine was more stable in transfersome cream than in non-transfersome cream. The average $\mathrm{N}$-acetylcysteine content remaining after accelerated stability testing for 3 months was $82.92 \%$ with a shelf life of 3 months 10 days in the transfersome cream and was $48.47 \%$ with a shelf life of 1 month 2 days in the non-transfersome cream. In addition, physical stability was relatively better in the $\mathrm{N}$-acetylcysteine transfersome creams than in the non-transfersome creams, as shown by the cycling test and centrifugal test results because there was no change in odor as observed for the non-transfersome creams. Future studies should attempt to identify substances that may be formed as a result of the degradation of $\mathrm{N}$-acetylcysteine in anti-aging creams formulated using transfersomes.

\section{CONFLICTS OF INTEREST}

All authors have none to declare.

\section{REFERENCES}

1. Allen LV, Popovich NG, Ansel HC. Pharmaceutical Dosage forms and Drug Delivery Systems. $9^{\text {th }}$ ed. Philadelphia, PA, USA: Lippincott Williams and Wilkins; 2011.

2. Mamta KM, Dhillon GS, Misra K, Brar SK, Verma M. Antioxidants. New York, USA: Springer; 2014.

3. $\mathrm{Wu} \mathrm{W}$, Abraham L, Ogony J, Matthews R, Goldstein G, Ercal N. Effect of N-acetylcysteine amide (NACA), a thiol antioxidant on radiation-induced cytotoxicity in Chinese hamster ovary cells. Life Sci 2008;82:1122-30.

4. Aldini G, Altomare A, Baron G, Vistoli G, Carini M, Borsani L, et al. $\mathrm{N}$-acetylcysteine as an antioxidant and disulphide breaking agent: The reasons why. Free Radic Res 2018;52:751-62.

5. Becker K, Haack D, Behzadi SS, Zimmer A. Oral Pharmaceutical 
Composition Comprising Taste-masked N-acetylcysteine. USA: World Intellectual Property Organization; 2014.

6. The United States Pharmacopeial Convention. United States Pharmacopeia and the National Formulary. Rockville, MD: The United States Pharmacopeial Convention; 2018.

7. Devi JA, Venkateshan N, Devi M. Analytical method development and validation of acetylcysteine and taurine tablet dosage form by using RP-HPLC. Indo Am J Pharm Sci 2018;5:717-26.

8. Harmita H. Buku Ajar Analisis Fisikokimia: Kromatografi. Jakarta, Indonesia: EGC Press; 2015

9. El Zaafarany GM, Awad GA, Holayel SM, Mortada ND. Role of edge activators and surface charge in developing ultradeformable vesicles with enhanced skin delivery. Int J Pharm 2010;397:164-72.

10. Goindi S, Kumar G, Kumar N, Kaur A. Development of novel elastic vesicle-based topical formulation of cetirizine dihydrochloride for treatment of atopic dermatitis. AAPS PharmSciTech 2013;14:1284-93.

11. Aashiq AS, Nimmy EG, Saravanan T. N-acetylcysteine, a boon for yellow phosphorus-induced acute liver failure? A case report. Asian J Pharm Clin Res 2019;12:1-3.

12. Al-Shuwaili AH, Rasool BK, AbduLrasool AA. Optimization of elastic transfersomes formulations for transdermal delivery of pentoxifylline. Eur J Pharm Biopharm 2016;102:101-14

13. Iskandarsyah I, Rahmi AD, Pangesti DM. Comparison of characteristics of transfersomes and protransfersomes containing azelaic acid. J Young Pharm 2018;10:11-5

14. Chaudhary H, Kohli K, Kumar V. Nano-transfersomes as a novel carrier for transdermal delivery. Int J Pharm 2013;454:367-80.

15. Ramadon D, Harme M, Anwar E. formulation of transfersomal green tea (Camellia sinensis L. Kuntze) leaves extract cream and in vitro penetration study using Franz diffusion cell. J Young Pharm 2018;10:63-8.

16. Bernhardt LK, Bairy KL, Madhyastha S. N-acetylcysteine reverses late gestational stress induced maternal oxidative damage. Int J Pharm Pharm Sci 2014;7:165-8
17. The-Phung T, Ellis AG, Ching MS, Shilson AD, Kong DC, Garrett K. Stability of a Formulated N-acetylcysteine capsule for prevention of contrast-induced nephropathy. J Pharm Pract Res 2008;38:219-22.

18. Suntres ZE. Liposomal antioxidants for protection against oxidantinduced damage. J Toxicol 2011;2011:152474.

19. Mishra K, Ojha H, Chaudhury NK. Estimation of antiradical properties of antioxidants using DPPH assay: A critical review and results. Food Chem 2012;130:1036-43.

20. Rahman MH, Hussein LA, El-Kosay AM. Comparative study of the antioxidant activity of phytosterols, DL methionine and N-acetylcysteine. Nat Prod Indian J 2010;6:213-20.

21. Shekhar TC, Anju G. Antioxidant activity by DPPH radical scavenging method of Ageratum conyzoides Linn. Leaves. Am J Ethnomed 2014;1:244-9.

22. Szychowski KA, Rybczynska-Tkaczyk K, Leja ML, Wojtowicz AK, Gminski J. Tetrabromobisphenol a (TBBPA)-stimulated reactive oxygen species (ROS) production in cell-free model using the 2',7'-dichlorodihydrofluorescein diacetate (H2DCFDA) assaylimitations of method. Environ Sci Pollut Res Int 2016;23:12246-52.

23. Phongpaichit S, Nikom J, Rungjindamai N, Sakayaroj J, HutadilokTowatana N, Rukachaisirikul V, et al. Biological activities of extracts from endophytic fungi isolated from Garcinia plants. FEMS Immunol Med Microbiol 2007:51:517-25.

24. Bharadia PD, Modi CD. Transfersomes: New dominants for transdermal drug delivery. Am J Pharm Tech Res 2012;2:1-5.

25. Jacob L, Anoop KR. A review on surfactants as edge activators in ultradeformable vesicles for enhanced skin delivery. Int J Pharm Bio Sci $2013: 4: 337-44$

26. Elsayed MM, Abdallah OY, Naggar VF, Khalafallah NM. Deformable liposomes and ethosomes: Mechanism of enhanced skin delivery. Int J Pharm 2006;322:60-6.

27. Miatmoko A, Kawano K, Hattori Y, Yonemochi E. Evaluation of transfersome and protransfersome for percutaneous delivery of cisplatin in hairless mice. J Pharm Pharmacol 2015;1:10-21. 